\title{
Meaningful Work, Quality of Work-life, and Job Satisfaction: A Study of Nightlife Workers
}

\author{
Sudin \& Yohanes Budiarto \\ Universitas Tarumanagara, Fakultas Psikologi, Jakarta, INDONESIA
}

Received: 13 May 2021 - Accepted: 30 July 2021 • Published Online: 14 August 2021

\begin{abstract}
Work is a means for man to fulfill their needs. However, from the positive psychology point of view, work is more than to fulfill the needs but beyond that reason. Work experiences provide added value to man's lives and societal growth. Nightlife industries are hardly researched even though these industries have been growing vastly. Workers in these areas are similar to other workers from different types of industries in that they make meaning of their work and experience job satisfaction and quality of their work-life. This research aimed at testing the contribution of the quality of work-life and meaningful work toward job satisfaction of female nightlife business workers. Path analysis using PLS-SEM shows that the job satisfaction of nightlife workers is predicted by their meaningful work and quality of work life. In this study, meaningful work acts as a mediator in the relationship between quality of work-life and job satisfaction.
\end{abstract}

Keywords: quality of work-life, job satisfaction, meaningful work, nightlife workers.

\section{Introduction}

A "sexually" oriented business industry is one industry sector that is rarely a concern in studies. Furthermore, the industry is formed in a disguised or even secretive manner so that the operations of this business are very seldom known (The Bureau of Business Research, 2009). Businesses in nightlife or adult entertainment can take various forms such as karaoke, house massage, and men's only spa, escort service, and discotheques. Nightlife entertainment like this has flourished, even reaching small towns and even suburbs in Indonesia.

Various skills and knowledge are needed in this industry. For example, every line of business requires professional security services, public relations skills, massage skills, customer service skills, IT specialists, on-site medical personnel, singers as karaoke guides, multi-media, and electrical experts. Of course, every worker following their respective fields has unique experiences gained from their work activities.

The majority of night entertainment workers are women. The Indonesian Law No. 13 of 2003 Article 5 on Manpower explains that "Every worker has equal opportunity without discrimination to get a job." This provision could be used as the basis for many women who choose to be involved as workers in the nightlife entertainment industry.

(C) Authors. Terms and conditions of Creative Commons Attribution 4.0 International (CC BY 4.0) apply. Correspondence: Sudin, Universitas Tarumanagara, Fakultas Psikologi, Jakarta, INDONESIA. E-mail: b.sudin.ng@gmail.com. 
Sudin \& Y. Budiarto - Meaningful Work, Quality of Work-life, and Job Satisfaction: ...

- Every worker, at some time, must have thought about their work and its impact on their life in general.

- Meaningful work has been shown to affect essential work engagement and job satisfaction.

- The value of work's purposes in people's views of life and attitudes can be linked to variables in organizational behavior.

Having a profession as a worker in adult nightclubs can lead to negative stereotypes for female workers. Of course, this will bring meaning to what they do as night entertainment workers and the meaning of their work environment.

Every worker, at some time, must have thought about their work and its impact on their life in general. Night entertainment workers are no exception to this. Night entertainment workers can interpret their work as something that is contributive to social or economic development. Through their work, night entertainment workers can also feel the meaning of achievement in their life. He can benefit from what he gets through his work to improve the welfare of his family or other people around him. This indicates the importance of having meaningful work for workers.

Frankl (1984) states that the search for meaning in life is the main power humans have in their lives. Through the meaning of life, a person can realize a goal in his life, which is the personal responsibility of that person. Work is a real action responsible for someone who realizes that work is a personal responsibility to achieve a meaningful life.

Geldenhuys and Venter (2014) state that because individuals spend a lot of time working, their work and work activities become one activity center for achievement in their lives. Therefore, it is essential to note that the work process, type of work, and workplace are areas of life where workers try to make sense of their work.

A good life goal is genuinely desirable, significant, meaningful, and valuable (Steger, Frazier, Oishi \& Kaler, 2006). The meaning of life is considered very important and valuable and gives special value to someone so that they are worthy of being a goal in life. When it is fulfilled, it will cause a person to feel meaningful life and, in the end, will cause a feeling of happiness (Bastaman, 2007). Those who think their life is meaningful have higher self-esteem and rarely experience depression and anxiety (Steger et al., 2006). One of the factors that can give meaning to someone's life is the meaningfulness of work.

There are articles on the nature of work that characterize meaningfulness as having many cognitive, mental, behavioral, and economic benefits and making essential and constructive changes to the meaning of people's lives. The value of work's purposes in people's views of life and attitudes can be linked to variables in organizational behavior (Hatice \& Mine, 2016).

Although there is no generally agreed concept of work, Baumeister and Vohs (2002) indicated that the heart of work was the sense of "bond" and relied on good outcomes for both the person and the organization. Meaningful work can be described as the positive and significant contribution that a job makes to an individual's sense of purpose in life and the happiness that a person derives from his or her job (Rosso, Dekas \& Wrzesniewski, 2010). Increased meaning of work can result in various cognitive, mental, behavioral, and economic benefits for individuals (Ardichvili, 2009; Steger, Dik \& Duffy, 2012). The true driver of interest in meaning, in this case, is the hypothesis that personal and organizational effects are linked to one's understanding of the meaning (Rosso et al., 2010).

A variety of management philosophies have recognized the significance of meaningful work over the last decade. It has been shown to affect essential work engagement (May, Gilson, \& Harter, 2004) and job satisfaction (Sparks \& Schenk, 2001). Meaningful work helps resolve the 
question, "Why am I here?" when something is essential (Pratt \& Ashforth, 2003). As measured by the individual's own values or expectations, the importance of a job goal or intention is known as meaningfulness (May et al., 2004). It is described as "the meaning made of, and importance felt about, the essence of one's being and being” in career literature. (Steger et al., 2006). Job satisfaction is higher for those who believe their work has a greater meaning and function (Kamdron, 2005).

The quality of work-life has become a concern of organizations, especially human resource development (Lian, $\mathrm{Lin} \& \mathrm{Wu}, 2007$ ). More and more employees are very concerned about the quality of life. Several studies have found a significant relationship between the quality of work-life and the meaning of life. If employees have a high-quality work-life, this can potentially lead to meaning in life; conversely, if the quality of work-life is low, it can potentially cause employee work stress. (Pisheh, 2012; Charu, 2013; Bolhari, Rezaeean, Bolhari \& Zare, 2012).

According to Paul E. Spektor (2003), job satisfaction has a reflective relationship with job stress. Several studies explain that there is a significant relationship between job satisfaction and meaningful life. Companies must continually maintain and pay attention to job satisfaction and the meaning of each employee's life (Manzoor, Usmar, Nassem \& Shafiq, 2011).

The research questions that need to be answered are: (1) Does the quality of work-life predict job satisfaction in the night entertainment industry? (2) Does the quality of work-life predict meaningful work in the night entertainment industry? (3) Does the meaningful work of workers predict job satisfaction in the night entertainment industry? and (4) Does meaningful work play a role as a mediator in the relationship between quality of work-life and job satisfaction in the night entertainment industry?

Four primary hypotheses in this study are:

$\mathrm{H}_{1}$. The quality of work-life predicts job satisfaction in the night entertainment industry.

$\mathrm{H}_{2}$. The quality of work-life predicts the meaningful work of workers.

$\mathrm{H}_{3}$. The meaningful work of workers predicts job satisfaction in the night entertainment industry.

H4. The meaningful work mediates the relationship between quality of work-life and job satisfaction of workers in the night entertainment industry.

\section{Method}

\subsection{Participants}

Participants involved in this study were female men-only spa therapists, amounting to 87 participants. Their mean age was 24.20 years $(\mathrm{SD}=4.074)$. The majority of participants have a high school education background, as described in Table 1.

Table 1. The participants' educational background

\begin{tabular}{lll}
\hline Education & Frequency & Percentage (\%) \\
\hline Elementary & 3 & $3.4 \%$ \\
Junior High School & 28 & $32.2 \%$ \\
Senior High School & 47 & $54 \%$ \\
Academy & 3 & $3.4 \%$ \\
Undergraduate & 6 & $6.9 \%$ \\
\hline Total & 87 & $100 \%$ \\
\hline
\end{tabular}




\subsection{Instruments}

We used the work and meaning inventory (WAMI) developed by Steger, Dik \& Duffy (2012) to measure the meaningfulness of work. WAMI has three dimensions, namely positive meaning, meaning-making through work, and greater good motivation. The positive meaning dimension measures the level of meaningfulness of work based on the individual's meaning, significance, and goals at work. The meaning-making through work emphasizes the broader meaning of the individual in his work. In this dimension, the individual tries to interpret his work as a source of experience in his life. Finally, the greater good motivation measures how much individuals value the efforts made in work to contribute positively to society at large. The three dimensions can be added together to produce a total score of meaningful work. The score reflects how meaningful work is to individuals, the amount of investment the individual has invested in his life (work as an investment), and considers it a source that enriches his life. Respondents use a 5-point scale ranging from absolutely untrue to absolutely true to rate the scale's items.

The instrument used to measure the quality of work-life was adapted from Donaldson, Sussman, Dent, Severson and Stoddard (1999). The QWL scale consists of six items describing six dimensions or aspects. The six dimensions are (a) my workplace provides a good working environment for its employees (my company provides a good working environment for its employees), (b) I am happy working at my workplace at this time (I am happy at my company), (c) my job does not stress me (my work is not stressful), (d) I have good relations with every coworker in my workplace (I get along well with my co-workers), (e) I get supervision good from my supervisor (I have good supervision at work), and (f) I feel my career is safe (my job security is good).

We used the Minnesota Satisfaction Questionnaire (MSQ) to measure job satisfaction. The Minnesota Satisfaction Questionnaire (MSQ) consists of two dimensions, namely intrinsic (14 items) and extrinsic (6 items). The MSQ has 20 items based on job satisfaction characteristics. The scale uses five response categories from not satisfied (1) to extremely satisfied (5).

\section{Results}

\subsection{Meaningful work description}

Descriptive statistical analysis on the Work and Meaning Inventory (WAMI) shows that no item has a standard deviation (SD) value which is extreme; namely, the standard deviation (SD) on each dimension is not <0.5. The meaningful work variable has three categorizations, namely: (1) low, with the formula $(X \leq \mu-\sigma)$; (2) moderate, with the formula $(\mu-\sigma<X \leq \mu+\sigma)$; and high with the formula $(X>\mu+\sigma)$. Classification of the low category is at a score of $\leq 1.724$; the medium is at a score range between 1.724 and 3.908, and the high is at a score of $>3.908$. Table 2 presents the classification of the participants' meaningful work variable.

Table 2. Category meaningful work dimension

\begin{tabular}{llll}
\hline Dimension & M & SD & Category \\
\hline Positive Meaning & 2.816 & 1.09233 & Moderate \\
Meaning Making Through Work & 3.086 & 1.38976 & Moderate \\
Greater Good Motivation & 5.506 & 1.07095 & High \\
\hline
\end{tabular}

Based on the classification above, the positive meaning dimension of the participants is moderate; meaning-making through work is categorized as moderate, and participants' greater good motivation is high. 


\subsection{Quality of work-life description}

The quality of work-life variable has three categorizations, namely: (1) low, with the formula $(X \leq \mu-\sigma)$; (2) moderate, with the formula $(\mu-\sigma<X \leq \mu+\sigma)$; and high with the formula $(\mathrm{X}>\mu+\sigma)$. Classification of the low category is at a score of $\leq 2.538$; the medium category is at a score of 2.538 - 3.220; the high category is at a score of $X>3.2200$. From Table 3, the participants' quality of work-life is categorized moderate.

Table 3. Calculation of standard deviation (SD) per dimension

\begin{tabular}{llll}
\hline Dimension & $\mathrm{M}$ & $\mathrm{SD}$ & Category \\
\hline Wellness & 2.8793 & 0.3407 & Moderate \\
Save Environment & 2.9847 & 0.3170 & Moderate \\
Employee Participation & 2.9579 & 0.3325 & Moderate \\
Equitable Compensation & 2.6954 & 0.5065 & Moderate \\
Communication & 3.0728 & 0.3715 & Moderate \\
Career Development & 2.9052 & 0.3836 & Moderate \\
Conflict Resolution & 3.0529 & 0.3665 & Moderate \\
Job Security & 2.8391 & 0.3451 & Moderate \\
Pride & 2.8456 & 0.2964 & Moderate \\
QWL Total & 2.9148 & 0.1879 & Moderate \\
\hline
\end{tabular}

\subsection{Job satisfaction description}

Job satisfaction consists of three categorizations, namely: (1) low, with the formula (X $\leq \mu-\sigma)$; (2) moderate, with the formula $(\mu-\sigma<X \leq \mu+\sigma)$; and height with the formula $(X>\mu+\sigma)$. Classification of the low category is at a score of $\leq 2,685$, the medium category is at a score of 2.6854.003, and the high category is at $\mathrm{X}>4,003$. The following is a table that describes the frequency of the participants' overall job satisfaction.

Table 4. Category job satisfaction dimension

\begin{tabular}{llll}
\hline Dimension & M & SD & Category \\
\hline Intrinsic Job Satisfaction & 3.2701 & 0.66414 & Moderate \\
Extrinsic Job Satisfaction & 3.4195 & 0.72642 & Moderate \\
\hline
\end{tabular}

\subsection{Measurement model of the study}

\subsubsection{Reflective measurement model}

Composite reliability, indicator reliability, convergent validity, and discriminant validity should be tested for reflective measurement models in which latent variables describe behavioral concepts such as job satisfaction, quality of work-life, and meaningful work. Table 5 shows the quality criteria of the measurements.

Table 5. The quality criteria of the measurements

\begin{tabular}{lllll}
\hline Variable & Cronbach's Alpha & Rho A & $\begin{array}{l}\text { Composite } \\
\text { Reliability }\end{array}$ & $\begin{array}{l}\text { Average Variance } \\
\text { Extracted (AVE) }\end{array}$ \\
\hline Job satisfaction & .896 & .900 & .950 & .906 \\
Meaningful work & .785 & .828 & .867 & .686 \\
QWL & .902 & .906 & .925 & .674 \\
\hline
\end{tabular}


Convergent validity is the degree to which metrics belonging to the same latent variable evaluate the same construct. The average variance extracted (AVE), which is commonly used to determine convergent validity, shows how much of the variance in the variables can be interpreted by the latent variable. An AVE greater than 0.5 has been proposed as an observational justification for convergent validity, as the resulting latent variable describes more than half of the variation in the belonging metrics. Therefore, all other latent variables explain less than half. The AVE values show a value greater than 0.5, which means that the convergent validity has been fulfilled.

Discriminant validity implies that two latent variables intended to describe two distinct theoretical ideas are statistically distinct. The HTMT should be less than 0.85 (stricter threshold) or 0.90 (softer threshold) or slightly less than 1. The HTMT of meaningful work to job satisfaction in our case is 0.496 , which is less than the suggested threshold of 0.85 . (and of 0.90). However, the quality of work-life to job satisfaction does not show good discriminant validity because the value is 1.04 over 1.00 .

Cronbach's and Dillon (also Goldstein's known as Jöreskog's or composite reliability) coefficients can be used to measure the reliability of the constructs. A Dijkstra-A Henseler's value greater than 0.707 is considered rational since the latent variable will explain more than 50\% of the variation in the constructs. All of the variables composite reliabilities are bigger than 0.707 . Therefore, the composite reliabilities are good.

The outer loadings inform the indicator loadings. The outer loading calculations can be used to determine indicator reliability. Since PLS standardizes factor loading calculations, the squared factor loading estimation equals the expected indicator reliability. It is commonly recommended that factor loadings be greater than 0.7 , meaning that the resulting latent variable will explain more than $50 \%$ of the variance in a single predictor. Table 6 presents the outer loadings of the variables. Table 6 . The outer loadings of the constructs have reached the minimum criteria of good indicator loading.

Table 6. The outer loadings of the variables

\begin{tabular}{llll}
\hline Variables & Job satisfaction & $\begin{array}{l}\text { Meaningful } \\
\text { work }\end{array}$ & QWL \\
\hline Extrinsic & 0.948 & & \\
Greater Good & & 0.771 & \\
Intrinsic & 0.956 & & \\
Meaning Making Through & & 0.824 & \\
Work & & 0.887 & \\
Positive Meaning & & 0.700 \\
QWL1 & & 0.810 \\
QWL2 & & 0.848 \\
QWL3 & & 0.868 \\
QWL4 & & 0.899 \\
QWL5 & & 0.788 \\
QWL6 & & & \\
\hline
\end{tabular}

\subsubsection{Composite model test}

The composite model necessitates examining the composite model in terms of multicollinearity. Since high multicollinearity can lead to insignificant estimates and unexplained weights, collinearity among indicators forming an emergent variable should be investigated using 
the variance inflation factor (VIF). The VIF values greater than five (5) are considered to be indicators of multicollinearity. Table 7 shows the VIF values of each dimension.

Table 7. The VIF values

\begin{tabular}{ll}
\hline \multicolumn{1}{c}{ Dimensions } & VVIF \\
\hline Extrinsic & 2.928 \\
Greater Good & 2.245 \\
Intrinsic & 2.928 \\
Meaning Making Through Work & 1.338 \\
Positive Meaning & 2.519 \\
QWL1 & 1.973 \\
QWL2 & 2.525 \\
QWL3 & 3.825 \\
QWL4 & 3.227 \\
QWL5 & 4.702 \\
QWL6 & 2.319 \\
\hline
\end{tabular}

The VIF values for the composite model indicators range from 1.973 to 4.702 , indicating that multicollinearity is not an issue in our results.

\subsection{Structural model of the study}

In assessing the structural model, we looked at the overall fit of the estimated model, the direction coefficient path, their significance and the effect sizes $\left(f^{2}\right)$. To gain empirical evidence for the suggested hypothesis, we first determine the overall fit of the estimated model using the bootstrap-based test of overall model fit and the SRMR as a metric of approximate fit.

The SRMR (0.090) was more than the suggested threshold of o.o80, meaning that the model fit was not adequate. This finding implies that the proposed model is not well suited for verifying and describing the quality of work-life capabilities to predict job satisfaction mediated by meaningful work. This bias might be due to the small sample size (Baron \& Kenny, 1986).

The effect size is a measure of an effect's significance that is independent of sample size. The $\mathrm{f}^{2}$ values ranging from 0.020 to $0.150,0.150$ to 0.350 , or greater or equal to 0.350 , respectively, indicate a small, medium, or high impact scale.

Table 7. The f square

\begin{tabular}{llll}
\hline Variables & Job satisfaction & Meaningful work & QWL \\
\hline Job satisfaction & & & \\
Meaningful work & 0.261 & & \\
QWL & 7.597 & 0.124 & \\
\hline
\end{tabular}

In our study, the $\mathrm{f}^{2}$ values for hypothesized relationship ranging from 0.124 to 7.597 . Meaningful work effect size to job satisfaction is medium, the effect size of QWL to job satisfaction is high, and the effect size qwl to meaningful work is small.

Figure 1.

The structural model test of the path of coefficients among variables is presented in 


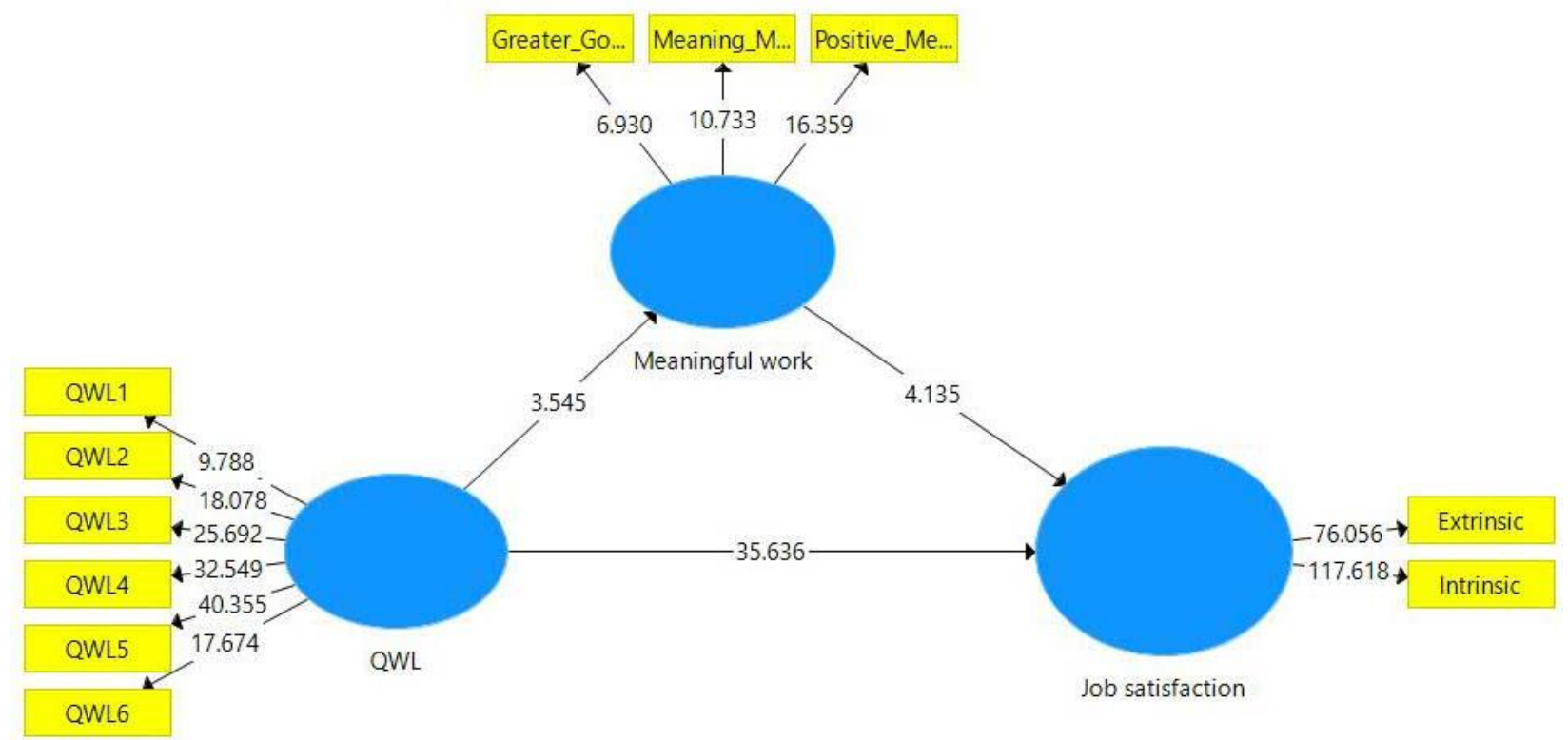

Figure 1. The structural model test

More detailed information regarding path analysis and its coefficients is summarized in Table 8. In testing the influence of meaningful work on job satisfaction, hypothesis testing proved that meaningful work has positive and significant effects on job satisfaction. $\mathrm{H}_{1}$ was supported. $\mathrm{H}_{2}$ is supported by the fact that QWL predicts job satisfaction positively. $\mathrm{H}_{3}$, which states that QWL has an impact on meaningful work, is also supported by the result.

Table 8. Mean, STDEV, T-Values, P-Values

\begin{tabular}{llllll}
\hline Path & $\begin{array}{l}\text { Original } \\
\text { Sample } \\
(\mathrm{O})\end{array}$ & $\begin{array}{l}\text { Sample } \\
\text { Mean (M) }\end{array}$ & $\begin{array}{l}\text { Standard } \\
\text { Deviation } \\
\text { (STDEV) }\end{array}$ & $\begin{array}{l}\text { T Statistics } \\
(\mid \mathrm{O} / \text { STDEV } \mid)\end{array}$ & $\begin{array}{l}\mathrm{P} \\
\text { Values }\end{array}$ \\
\hline $\begin{array}{l}\text { Meaningful work -> Job } \\
\text { satisfaction }\end{array}$ & 0.164 & 0.166 & 0.040 & 4.135 & 0.000 \\
$\begin{array}{l}\text { QWL -> Job satisfaction } \\
\begin{array}{l}\text { QWL -> Meaningful } \\
\text { work }\end{array}\end{array}$ & 0.886 & 0.883 & 0.025 & 35.636 & 0.000 \\
\hline
\end{tabular}

Hypothesis 4 is seen in Table 9. The role of QWL on job satisfaction was mediated by meaningful work, which revealed that meaningful work has a mediation impact on the relatiomnship between QWL and job satisfaction.

Table 9. Specific indirect effects

\begin{tabular}{lllllr}
\hline & $\begin{array}{l}\text { Original } \\
\text { Sample } \\
(\mathrm{O})\end{array}$ & $\begin{array}{l}\text { Sample } \\
\text { Mean } \\
(\mathrm{M})\end{array}$ & $\begin{array}{l}\text { Standard } \\
\text { Deviation } \\
\text { (STDEV) }\end{array}$ & $\begin{array}{l}\text { T Statistics } \\
(|\mathrm{O} / \mathrm{STDEV}|)\end{array}$ & P Values \\
\hline QWL -> Meaningful work -> Job satisfaction & 0.054 & 0.058 & 0.019 & 2.922 & 0.004 \\
\hline
\end{tabular}

\section{Discussion}

Studies related to QWL, the meaning of work, and job satisfaction have never touched a work organization that manages a nightlife business. This study is perhaps the first to explore how the three variables are related. 
The classic definition of QWL by Lawler (1982) is described as being linked to job characteristics and work environments since the overall aim of QWL in the company was to increase employee well-being and productivity support. According to Serey (2006), QWL is synonymous with meaningful and satisfying work. It includes the ability to put one's talents and skills to use in the face of obstacles and circumstances that necessitate self-initiative and selfdirection.

QWL is a holistic definition of physical and psychological well-being, economic circumstances, personal belief, and environmental contact. In contemporary management, the concept of job quality has been transformed into a social problem, while in recent decades, only personal life has been stressed (Mirkamali \& Narenji Sani, 2008). The definition of job quality is subjective creativity and the opinion of organizational staff regarding the physical and psychological desirability of work environments and their work circumstances (Yavari, Amir Tash \& Tondnevis, 2009).

During 1980 to 2006, research was carried out on the quality of work-life and their results suggest that the quality of work-life is linked to certain factors, such as satisfaction with the job. Employment satisfaction is characterized as a concept, perception, and positive attitudes and emotions of people about the occupation influenced by certain factors such as working atmosphere, organizational structure, the job environment, and socio-cultural factors (Mirkamali \& Narenji Sani, 2008; Armstrong, 2006). Our study also finds that the quality of work-life predicts job satisfaction positively. Finally, it is undeniable that a high level of QWL contributes to work satisfaction, leading to excellent and productive efficiency.

This research was influenced by the idea of the meaning of work, which is a positive variable, and the relationship between levels of meaning of work and job satisfaction. As the results are analyzed, it is discovered that there is a major positive relationship between career value and job satisfaction. This result corroborates previous research indicating that job satisfaction is higher in people who believe their jobs have a greater function (Sparks \& Schenk, 2001; Kamdron, 2005).

\section{Conclusion}

This study aims to determine the dynamics of job satisfaction variables, meaningful work, and quality of work-life of workers in the night business. This study explores the relationship between the variables studied based on the role of mediation and tested by PLS-SEM in a different context from traditional studies related to job satisfaction, meaningful work, and quality of worklife variables. The results of the analysis show that the quality of work-life predicts meaningful work and job satisfaction. Meaningful work also indicates job satisfaction. In addition, meaningful work acts as a mediator between the quality of work-life relationships and job satisfaction. These findings suggest that the study of the quality of work-life, meaningful work, and job satisfaction in the context of the adult nightlife business is also in line with traditional studies of all these variables in the normative business and organization context.

\section{Acknowledgements}

This research did not receive any specific grant from funding agencies in the public commercial, or not-for-profit sectors.

The authors declare no competing interests. 


\section{References}

Ardichvili, A. (2009). The relationship between meaning of working and socioeconomic transformations: The case of post-communist Russia. Advances in Developing Human Resources, 11(2), 218234. https://doi.org/10.1177/1523422309332244

Armstrong, M. (2006). A handbook of human resource management practice (10 ${ }^{\text {th }} \mathrm{ed}$.). London, England: Kogan Page Publishing.

Baron, R. M., \& Kenny, D. A. (1986). The moderator-mediator variable distinction in social psychological research: Conceptual, strategic, and statistical considerations. Journal of Personality and Social Psychology, 51(6), 1173-1182. https://doi.org/10.1037/0022-3514.51.6.1173

Bastaman, H. D. (2007). Logoterapi: Psikologi untuk menemukan makna hidup dan meraih hidup bermakna. Jakarta: PT Raja Grafindo Persada.

Baumeister, R. F., \& Vohs, K. D. (2002). The pursuit of meaningfulness in life. In C. R. Snyder \& S. J. Lopez (Eds.), The handbook of positive psychology. Oxford: Oxford University Press.

Bolhari, A., Rezaeean, A., Bolhari, J., \& Zare, F. (2012). The impact of occupational stress on quality of work life among the staff of e-workspace. world academy of science, engineering and technology. International Journal of Social, Behavioral, Educational, Economic, Business and Industrial Engineering, 6, 1739-1743.

Charu, M. (2013). Effect of occupational stress on QWL: Amongst the associates of IT Industry. Advances In Management, 6(5), 43-48.

Donaldson, S. I., Sussman, S., Dent, C. W., Severson, H. H., \& Stoddard, J. L. (1999). Health behavior, quality of work life, and organizational effectiveness in the lumber industry. Health Education \& Behavior, 26(4), 579-591. https://doi.org/10.1177/109019819902600413.

Frankl, V. E. (1984). Man's search for meaning: An introduction to logotherapy (3 ${ }^{\text {rd }}$ ed.). New York, NY: Touchstone.

Geldenhuys, M., Laba, K., \& Venter, C. M. (2014). Meaningful work, work engagement and organisational commitment. SA Journal of Industrial Psychology, 4O(1), 1-10. https://doi.org/10.4102/sajip.v40i1.1098

Hatice, N. K., \& Mine, A.F (2016). The effect of the meaningfulness of work on job satisfaction, job stress and intention to leave. Global Journal of Business, Economics and Management: Current Issues, 6(3), 61-69.

Kamdron, T. (2005). Work motivation and job satisfaction of estonian higher officials. International Journal of Public Administration, 28, 1211-1240. https://doi.org/10.1080/01900690500241085

Lawler, E. E. (1982). Strategies for improving the quality of work life. American Psychologist, 37(5), 486493. https://doi.org/10.1037/0003-066X.37.5.486

Lian, W., Lin, M., \& Wu, K. (2007). Job stress, job satisfaction and life satisfaction between managerial and technical is personnel. Proceedings of Business and Information, 4, 1-17.

Manzoor, M. U., Usman, M., Nassem, M. A., \& Shafiq, M. M. (2011). A study of job stress and job satisfaction among universities faculty in Lahore, Pakistan. Global Journal of Management and Business Research, 11(9), 12-16.

May, D. R., Gilson, R. L., \& Harter, L. M. (2004). The psychological conditions of meaningfulness, safety and availability and the engagement of the human spirit at work. Journal of Occupational and Organizational Psychology, 77(1), 11-37. https://doi.org/10.1348/096317904322915892 
Mirkamali, S., \& Narenji, S. F. (2008). A study on the relationship between the quality of work life and jab satisfaction among the faculty members of Tehran and Sharif University of Technology. Journal of Research and Planning in Higher Education, 48(1), 73-96.

Pisheh, M. H. M. (2012). Quality of work-life and job stress among Iran public employees, AJBM,6 (28), 8296-8308. https://doi.org/10.5897/11.1091

Pratt, M. G., \& Ashforth, B. E. (2003). Fostering meaningfulness in working and at work. In K. S. Cameron, J. E. Dutton \& R. E. Quinn (Eds.), Positive organizational scholarship: Foundations of a new discipline (pp. 309-327). San Francisco, CA: Berret-Koehler.

Rosso, B. D., Dekas, K. H., \& Wrzesniewski, A. (2010). On the meaning of work: A theoretical integration and review. Research in Organizational Behavior, 30, 91-127.

Serey, T. T. (2006). Choosing a robust quality of work life, Business Forum, 27(2), 7-10

Sparks, J. R., \& Schenk, J. A. (2001). Explaining the effects of transformational leadership: An investigation of the effects of higher-order motives in multilevel marketing organizations. Journal of Organizational Behavior, 22, 849-869.

Steger, M. F., Dik, B. J., \& Duffy, R. D. (2012). Measuring meaningful work: The work and meaning inventory (WAMI). Journal of Career Assessment, 20(3), 322337. https://doi.org/10.1177/1069072711436160

Steger, M. F., Frazier, P., Oishi, S., \& Kaler, M. (2006). The meaning in life questionnaire: Assessing the presence of and search for meaning in life. Journal of Counseling Psychology, 53, 80-93. https://doi.org/10.1037/00220167.53.1.80

The Bureau of Business Research (2009). An assessment of the adult entertainment industry in Texas. University of Texas, Austin.

Yavari, U., Amir Tash, A., \& Tondnevis, F. (2009). Compare the quality of working life and its subscales in the faculty of physical education colleges and public universities. Journal of Movement and Exercise Science, 7(1), 99-109. 
Sudin \& Y. Budiarto - Meaningful Work, Quality of Work-life, and Job Satisfaction: ...

C O A $\mathrm{s}$ 